\title{
Using the "Identifying a Pattern" Strategy to Solve Mathematical Word Problems of Proportional Quantities at Grade 5 - Vietnam
}

\author{
Ngo Truc Phuong ${ }^{1}$, Nguyen Phu Loc ${ }^{2, *}$ \\ ${ }^{1}$ Faculty of Education, Bac Lieu University, Bac Lieu City, Vietnam \\ ${ }^{2}$ School of Education, CanTho University, Can Tho City, Vietnam \\ *Corresponding Author: nploc@ctu.edu.vn \\ Received October16, 2019; Revised December 13, 2019; Accepted December 17, 2019
}

Copyright $\odot 2020$ by authors, all rights reserved. Authors agree that this article remains permanently open access under the terms of the Creative Commons Attribution License 4.0 International License

\begin{abstract}
Ratios and proportions that describe relationships between quantities are the foundation for students to understand and develop many concepts and skills in mathematics. Therefore, they play an important role in students' learning Mathematics. This paper will present the results of the comparis on of mathematical word problems relating to proportional quantities in Mathematics textbooks of Vietnam and USA from the perspective of pattern identification. It also indicates that the design and implementation of some activities to teach the word problems in which the analysis to identify patterns is a necessary strategy. The study results revealed that using "identifying a pattern" problems is a useful tool to promote problem - solving competency for elementary schoolstudents in Vietnam.
\end{abstract}

Keywords Identifying a Pattern, Mathematical Word Problem, Mathematical Pattern, Proportion, Proportional Quantities, Solving Mathematical Word Problem

\section{Introduction}

In a study about students' difficulties in solving mathematical word problems from their teachers' perspectives, Seifi et al. (2012) showed that students in elementary grades had a weak foundation because their teachers taught them inappropriate strategies. In order to overcome students' difficulties, most of the teachers suggested helping students in teaching them to look for a pattern. New Jersey Mathematics Curriculum Framework (1997) emphasizes that every Mathematics teacher needs to assist students in recognizing, generalizing, and using patterns that exist in numbers, in shapes, and in the world around them.
It can be seen that identifying patterns in solving problems is considered as a helpful strategy. Patterns often appear in Primary Mathematics te xtbooks of America and Singapore with a variety of activities, such as identifying rules, extending patterns and solving word problems with patterns. However, in Vietnamese primary te xtbooks, the authors have not seen solving problems, where looking for a pattern is a strategy.

According to the trend of international integration, Vietnamese education is implementing a curriculum, which transforms content-based instruction to competency-based education. Therefore, enhancing problem solving competency for primary students becomes an essential element in teaching and learning goals of "General Education Program: Mathematics" in Vietnam. In order to solve problems effectively, ele mentary students need to be provided with discovery tools, including the strategy of looking for a pattern.

In this article, from analyzing using "identifying a pattern" in solving word problems relating to proportional quantities in textbooks and implementing an experiment with Grade 5 students, the authors believe that using patterns could bring more fruitful for students in solving mathematical word problems.

\section{Literature Review}

\subsection{Problems of Identifying a Pattern}

A mathematical pattern can be described as any predictable regularity, usually involving nu merical, spatial or logical relationships. In every pattern, the various elements are organized in some regular fashion. Once a pattern is established, it is easy to predict what happens next because a pattern can be extended or continued after it 
has been identified (Mulligan, 2009).

According to Warren, "The power of mathe matics lies in relations and transformations which rise to patterns and generalizations. Abstracting patterns are the basics of structural knowledge and the goal of mathematics learn ing" (cited by Mulligan, 2009). Because the patterns can be found everywhere - in nature, numbers, and in shape, the strategy of looking for a pattern is one of the most frequently used strategies in solving mathematics problems.

Pattern-based thinking, using patterns to analyze and solve problems, is a powerful tool for doing mathe matics in primary schools level. It is suitable for describing relationships and making the foundation for further work on with algebraic functions in higher grades. In grade 5-6 levels, the key components of pattern-based thinking are exploring, analyzing, and generalizing patterns, viewing rules and input/output situations as functions (New Jersey Mathematics Curriculum Framework, 1997, p.345). In ele mentary schools, the strategy of looking for a pattern is an extension of Drawing a Table and Creating an Organized List. These are two strategies used in solving mathematics problems.

Loc (2016) proposed the following model of identify ing a pattern (see Figure 1).

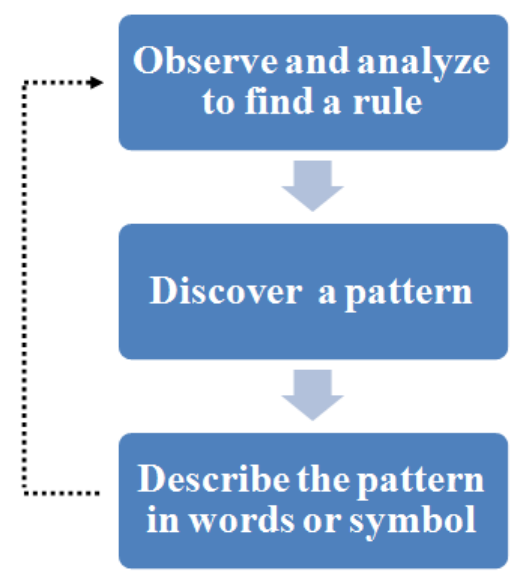

Figure 1. Model of identifying a pattern (Loc, 2016)

In the problem of "identifying a pattern", students need to find a rule fro $m$ the connection of the data with the given information. Once the pattern has been identified, students can predict what will happen next to find the solution.

To solve problems based on identifying a pattern, students have two indispensable requirements, including (1) determining quantities in the problem and the relationship between them, (2) using visual representations, words, symbols or numbers to describe the rule.

When students are faced with non-routine problems that have no standard method to solve, they usually give up easily because they do not know how to get started. The ability to discover and analyze patterns becomes a critical tool to help them be oriented. At this time, the problem of "identifying a pattern" is a part of the process of solving non-routine problems.

The process of solving a problem using the "identify ing a pattern" strategy can be performed as follows:

- List the given information and identify the required information.

- Make an organized list or create a table.

- Determine the rule through analyzing data (the process of "identifying a pattern").

- Use the pattern to find the missing information and direct to the correct solution to the problem.

\subsection{A Comparison between Textbooks of Vietnam and America on Word Problems Relating to Proportional Quantities from the Perspective of Pattern Identification}

In this part, the authors present results of the comparison between Go Math Grade 5 \& Grade 6 (A merican te xtbooks) and Toan 5 (Vietnamese textbook) about problems of directly proportional quantities (name in Vietnamese).

In American mathematics curriculum, from Kindergarten to high school, looking for a pattern is considered one of the strategies that are needed to equip students in solving mathematical problems in general and word problems in particular. The level of the critical components of pattern-based thinking is identified to be more and more complicated at the higher grades. Students develop higher-level thinking throughout their work with patterns in many types of problems. According to NCTM (2000), in grades 5-6, students express understanding of patterns, relations, and functions as follows: (1) Describe, extend, and make generalizations about geometric and numeric patterns; (2) Represent and analyze patterns and functional relationships using words, tables, and graphs.

In Go Math Grade 5, the numerical pattern is part of the standards of computational and algebraic thinking. Identifying a pattern is one of the strategies used to solve word problems of proportional quantities. The example is illustrated in the figure below (see Figure 2). 
When Alice completes each level in her favorite video game, she wins 3 extra lives and 6 gold coins. What rule can you write to relate the number of gold coins to the number of extra lives she has won at any level? How many extra lives will Alice have won after she completes 8 levels?

\begin{tabular}{|c|c|c|c|c|c|c|c|c|}
\hline Level & 0 & 1 & 2 & 3 & 4 & $\ldots$ & 8 & \\
\hline Extra Lives & 0 & 3 & 6 & 9 & 12 & $\ldots$ & & Multiply by \\
\hline Gold Coins & 0 & 6 & 12 & 18 & 24 & $\ldots$ & 48 & divide by \\
\hline
\end{tabular}

Figure 2. Problem 1 of identifying a pattern (Go Math Grade 5, p.560)

In the above problem, to assist students in finding answers, a table of numerical data representing relationships is proposed. In the table, there are 3 given values and other values adding to make 3 regular increasing sequences. There are two rules: (1) the number of extra lives is increased by 3 , and the number of gold coins is increased by 6 after a level; (2) the number of gold coins is twice as great as the number of extra lives in any level. The rules are described by words and symbols.

It can be seen that the common way to identify rules in a pattern according to Go Math Grade 5 is finding the difference between two consecutive numbers and finding out whether the numbers have been multiplied or divided by any given number. At the grade level, the concept of proportions or ratios does not appear in describ ing patterns.

Go Math Grade 6 continues to solving this type of problem with describing the pattern relating to equivalent ratios (see Figure 3).

$$
\frac{\text { gallons }}{\text { miles }} \rightarrow \frac{2}{12}=\frac{\square}{48} \leftarrow \frac{\text { gallons }}{\text { miles }}
$$

Make a table of equivalent ratios.

\begin{tabular}{|l|c|c|c|c|}
\multicolumn{1}{c}{$\begin{array}{c}\text { Original } \\
\text { ratio }\end{array}$} & $\begin{array}{c}2 \cdot 2 \\
\downarrow\end{array}$ & \multicolumn{2}{c|}{$\begin{array}{c}\downarrow \\
\downarrow\end{array}$} \\
\hline Gas used (gallons) & 2 & & 6 & \\
\hline Distance (miles) & 12 & 24 & & 48 \\
\hline & $\uparrow$ & $\uparrow$ & $\uparrow$ \\
\hline
\end{tabular}

Figure 3. Problem 2 of identifying a pattern (GoMath Grade 6, p. 235)

The problem asks to find the a mount of gas used to travel 48 miles if using 2 gallons can travel 12 miles. In the table, students have to find many numbers of a sequence whose rule is hidden. The numbers in columns 2 and 3 are intended to assist students in exploring the pattern faster. By addition to 2, students can find the missing number of gas used, but the answer is based on equivalent ratios

$$
\frac{2}{12}=\frac{\square}{48}
$$

Go Math Grade 6 also presents another case of equivalent ratios. That is finding a unit rate of two values. When solving problems, students can use a unit rate to find the unknown value. Finding a unit rate sometimes leads to a decimal number, for example

$$
\frac{30}{20}=\frac{\square}{24} \rightarrow \frac{30: 20}{20: 20}=\frac{\square}{24} \rightarrow \frac{1,5}{1}=\frac{\square}{24} \rightarrow \frac{1,5 \times 24}{1 \times 24}=\frac{\square}{24}
$$

(Go Math Grade 6, p.252)

In general, according to Go Math, the way to assist students in describing patterns is using a data table to represent terms of quantities. From the given values, students implement regular additions to consecutive terms of each quantity by the same number. Based on this rule, the relationship of multiple or ratio between two quantities is found out.

In order to solve the problem of proportional quantities, while Go Math focuses on using a pattern, Toan 5 presents two methods of verbally solving as follows:

- Method of rate mentions a rate of two values of the same quantity. For example, because 3 hours is three times as much as 1 hour, if travelling 4 kilometers is in 1 hour then travelling 12 kilometers is in 3 hours (in this case, 3 is a factor).

- Method of reducing to a unit aims to find the value of 1 unit. For example, if we travel 12 kilometers in 3 hours then in 1 hour ( 1 unit of time) we travel 4 kilometres, so in 5 hours we travel 20 kilometres.

When the value of 1 unit of a certain quantity is decimal, the method of reducing to the unit is not used because the problem of proportional quantities is learned earlier than the concept of decimal nu mbers. Besides, if the value of the quantity is not multiple of other quantity, students do not solve problems by the method of rate.

Toan 5 also illustrates two quantities that are directly proportional in the following data table in Figure 4. 


\begin{tabular}{|l|c|c|c|}
\hline Thời gian đi & 1 giờ & 2 giờ & 3 giờ \\
\hline Quãng đường đi được & $4 \mathrm{~km}$ & $8 \mathrm{~km}$ & $12 \mathrm{~km}$ \\
\hline
\end{tabular}

Nhận xét : Khi thời gian gấp lên bao nhiêu lần thi quãng đường đi được cũng gấp lên bấy nhiêu lẩn.

\begin{tabular}{|c|c|c|c|}
\hline Time (hour) & 1 & 2 & 3 \\
\hline Distance (kilometer) & 4 & 8 & 12 \\
\hline $\begin{array}{l}\text { Remark: if amount of time } \\
\text { increase, the distance also } \\
\text { increase by the same times. (Translated) }\end{array}$ \\
\hline
\end{tabular}

Figure 4. Illustration of two proportional quantities in Toan 5 (Toan 5, p.18)

In describing the relationship, the textbook does not explain the principle of regular addition by the same number to each term of quantity, nor does it mention the ratio or multiple between time and distance. The remark orients students towards two methods of verbal solving discussed above.

\subsection{Comments}

Through studying Go Math (Grades 5-6) and Toan 5, we can see some differences in solving problems of proportional quantities as follows (see Table 1):

Table 1. The differences in resolving problems between Go Math and Toan 5

\begin{tabular}{|l|l|}
\hline Go Math & Toan 5 \\
\hline Use patterns in solving stage & $\begin{array}{l}\text { Use words and operations in } \\
\text { solving stage }\end{array}$ \\
\hline $\begin{array}{l}\text { A unit rate of quantity is always } \\
\text { found; it can be a decimal } \\
\text { number. }\end{array}$ & $\begin{array}{l}\text { A unit rate of quantity is always } \\
\text { number. number, not a decimal }\end{array}$ \\
\hline $\begin{array}{l}\text { Find out the proportion of two } \\
\text { values in two quantities to } \\
\text { expand a pattern. }\end{array}$ & $\begin{array}{l}\text { Find rate (multiple times) of } \\
\text { two values in the same quantity }\end{array}$ \\
\hline
\end{tabular}

It can be seen that GoMath mentions three necessary aspects about proportions which Dougherty et al. (2017) indicated as follows

(1) The relationship between the quantities in a ratio is multiplication in nature (not addition);

(2) Although one of the numbers in the ratio is not a factor (or multiple) of the other number, a unit rate of quantity is always found;

(3) Equivalent ratios are not neces sary integral mu ltiples of another ratio.

In Toan 5, although there is only one table illustrating the proportional relationship, it clearly describes a numerical pattern. Most of the Vietnamese students are taught to solve problems of proportional quantities by either the method of rate or the method of reducing to a unit.
However, if the value of 1 unit is a decimal or there are no divisible relationships between the given values, both two these methods cannot be an option for students. Furthermore, it is not always clearly visible to recognize mu ltip le or div is ible re lationships between the given values if they are large numbers. As a result, students make errors in calculating, even give up solving problems.

\section{The Research Questions}

From the comments above, three research questions are posed as follows

1) In Vietnam, for solving problems of proportional quantities, how can the strategy of using the problem "identifying a pattern" be taught to fifth graders?

2) Are students interested in using the strategy of "identifying a pattern"?

3) Is using the strategy of "identifying a pattern" effective to proportional quantities problem?

\section{Methodology}

\subsection{Learning Activities}

To answer the three research questions above, we designed a study consisting of three learning activities in order to teach solving word problems of directly proportional quantities at Grade 5 by using the proble m of "identifying a pattern" (see Appendix)

\subsection{Participants}

Experimental subjects were 30 fifth graders in primary schools in Bac Lieu city. These students have not still learned the directly proportional quantities according to Math 5 curriculum. The study was carried out in October 2019.

\subsection{Teaching Activities}

In our study, there are three major activities carried out in 2 periods (70 minutes).

Because Grade 5 students have not learned about patterns, the first activity aims to introduce patterns, describe their rule in words, and extend them. Students approach the concept of the pattern via working out the problems in three given tables. In table 1, students identify a pattern relating to finding the relationship of map distance to the real distance, which was taught in Grade 4. Map distance and real distance have a directly proportional relationship. Table 2 is for two quantities that are not proportional, and students discover relationships between work time and the money earned $(+1$ in the terms of work time, +2 in the terms of money earned). Table 3 requires 
students to recognize the proportional relationship between the length and the width of the T-shirt. Another task in Activity 1 is identifying the equivalent ratios of quantities in each table for students to understand the ratio clearly. Through these illustrations of patterns, it is expected that the ratio of two directly proportional quantities is recognized.

The second activity aims to instruct students in the process of solving word problems by creating tables and using the "identifying a pattern" strategy. The problem designed has three tasks in relation to the proportional relationship between the number of books and the amount spent. In tasks (1) and (2), students can use the method of rate or the method ofreducing to a unit to find answers. For task (3), referring to the table with some given numbers describing the rule in words, students find all the missing numbers, and then find the answer to the task (2).

The third activity is for students to practice themselves on solving two problems. In Problem 1, two known methods are no longer effective; question $\mathrm{b}$ directs students towards finding smaller values and the unit rate. Proble $\mathrm{m} 2$ is more difficult because students need to find out two quantities, create a table, and discover relationships between them to get the answer.

After Activity 3, the teacher asks students to propose the general process used in solving word problems by using the "identifying a pattern" strategy. Finally, students are interviewed by asking the two following questions:

1) Do you like solving word problems with using the strategy of "identifying a pattern"? Why or why not?

2) Are there any difficulties you faced in solving word problems with using the "identifying a pattern" strategy?

\subsection{Results}

In Activity 1, students can quickly recognize rules and finish finding missing numbers. For Table 1, students discovered 3 types of pattern:

Answer 1: "The reald istance is always twice as long as the map distance" (17/30 students).

Answer 2: "When the map distance is increased by 3, the real distance is increased by 6" (10/30 students).

Answer 3: "The measure of map distance and real distance is increased by the same factor" (3/30 students).

Similarly, in Table 2, all students describe the rule of "the amount of earned money is increased by 2 after the number of time work is increased by 1". To find the amount of earned money for 10 hours, 10/30 students implemented multiplying the amount of earned money for 5 hours by 2 because they base on " 10 is a double of 5". Students' wrong answers indicate that they have not understood deeply about proportional quantities. The others who found the amount of earned money for 6, 7, 8, 9 hours before 10 hours have a true answer.

Students describe the rule in Table 3 as follows: "the length of each size is increased by 3 while the width is increased by 2 ". It is clearly shown that students did not pay attention to the ratio of the length to the width.

In Activity 2, students prioritize the method of reducing to a unit because they are familiar with this method in solving problems in previous grades. The first solving step is finding the price of a book which is $7000 \mathrm{VND}$, then multiplying the number of books by 7000 to find the amount of money buying 24 books, buying 9 books. So me students have difficulty in finding the number of books corresponding to $126,000 \mathrm{VND}$ due to the division of 126,000 by 7,000 . There were no students who chose " 24 is twice 12 " to find the amount of money for purchasing 24 books by multiplying the a mount of money purchasing for 12 books by 2 . It means that the rate of the numbers of books is not chosen the first time. However, after working with the table in task 3 , students get the answer by finding the amount of money for buying 9 books based on 3 books, 24 books based on 12 books. Although the rule in the table described as "the amount of spent money is always equal to the number of notebooks multiplied by 7000 " or "the number of money is 7000 times the number of books", students found missing numbers based on the multiplication relationship between terms of the same quantity.

In Problem 1 of Activity 3, based on "every 1500 people will increase by 30 people", students easily find out "every 500 people will increase by 10 people" and "every 50 people will increase by 1 person". From that, they fill in the table of numbers according to the rule of increasing and recognize "every 5000 people will increase by 100 people". Students also discovered that the ratio of increasing population in the town is 1 out of 50 .

In Problem 2 (Activity 3), students have difficulty in determining the variables and are confused about how to present the solution. After creating the table, some students find the answer but do not know how to present the solving process.

To sum up, almost students perform require ments well in Activities 1 and 2 like finding out the missing numbers and describing patterns. However, there are still some errors in words and meanings, such as "difference between the number of notebooks is 7,000 VND" and "when the amount of time work increases, the amount of money also increases". Students have some difficulties in deciding variables and presenting the solving process.

\section{Discussions and Conclusions}

After doing three learning activities with patterns, students find out the general process to solve problems by using pattern identification. It can be concluded that using patterns helps students realize the constant ratio relationship of two proportional quantities that the previous methods do not. Moreover, extending patterns overcome 
some limitations on finding multiples as well as factors.

According to the results of the interview, 30/30 students stated that solving problems by using the strategy of "identifying a pattern" is more comfortable than the method of reducing to a unit and present fewer errors in performing numerical operations because the numbers in the table have clear rules. They agree that pattern identification is an effective strategy for solving word problems. However, students also state that it is difficult to use words to describe patterns and present the solving process in non-routine problems. According to the common presentation in elementary school, each solution for a problem must always include the solution sentences and formula of numerical operations.

The positive results above indicate that Vietnamese students should be approached using the method of "identifying a pattern" in solving word problems as an effective strategy. Besides, it is essential to introduce both patterns of proportional and non-proportional quantities to encourage students to identify many types of patterns.

In Vietnam primary mathematical syllabus, before grade 5 , students are acquainted with the strategy of "identifying a pattern" relating to numbers, shapes, forming tables of addition and multiplication, but this is not exploited in solving word problems yet. From the experimental and survey results, we think that the teaching process designed above is relatively appropriate.

In conclusion, to develop students' problem solving competency through problem solving, it is very necessary to provide them strategies and tools, including the method of "identifying a pattern".

\section{Appendix}

\section{Activity 1: Familiarizing with the Patterns}

1. Describe the rule in the following tables and find the missing numbers:

*Table 1

\begin{tabular}{|c|c|c|c|c|c|}
\hline Distance in the map $(\mathrm{cm})$ & 3 & 6 & & $\ldots$ & 27 \\
\hline Real distance $(\mathrm{km})$ & 6 & 12 & 18 & $\ldots$ & \\
\hline
\end{tabular}

*Table 2

\begin{tabular}{|l|l|l|l|l|l|l|}
\hline Number of working hours & 1 & 2 & 3 & 4 & 5 & 10 \\
\hline Earned money (in dollars) & 4 & 6 & 8 & & & \\
\hline
\end{tabular}

*Table 3. The length and width of Viet Tien men's T-shirts are as follows

\begin{tabular}{|c|c|c|}
\hline Size & Length $(\mathrm{cm})$ & Width $(\mathrm{cm})$ \\
\hline S & 72 & 48 \\
\hline M & 75 & 50 \\
\hline L & & 52 \\
\hline XL & & 54 \\
\hline
\end{tabular}

2. In each of the above tables, do you comment on the ratio between the quantities in the given table?

\section{Activity 2: Solve Problems Using a Pattern Recognition}

Known that if you buy 12 notebooks, it costs 84,000 VND.

1. How much does it cost to buy 24 notebooks?

2. How much does it cost to buy 9 notebooks? If you have $126,000 \mathrm{VND}$, how many notebooks can you buy?

3. Given the following table:

\begin{tabular}{|c|c|c|c|c|c|c|c|}
\hline $\begin{array}{c}\text { Number of } \\
\text { notebooks }\end{array}$ & 1 & 2 & 3 & 6 & 12 & 24 & \\
\hline $\begin{array}{c}\text { Amount of } \\
\text { money (VND) }\end{array}$ & & & & & $\begin{array}{c}84 \\
\text { thousand }\end{array}$ & $\begin{array}{c}252 \\
\text { thousand }\end{array}$ \\
\hline
\end{tabular}

- $\quad$ Fill the appropriate number in the blanks.

- Describe the rule used to find the above numbers?

- Use this table to find the answer to question 2?

\section{Activity 3: Solving Math Problems}

1. Commune A has a population growth rate according to the law: after 1 year for every 1,500 people, an increase of 30 people. Ask if this commune has 5000 people, at this time next year how many more people will increase?

a. Fill the given data in the following table:

\begin{tabular}{|l|l|l|l|l|l|}
\hline Number of existing people & & & & & \\
\hline $\begin{array}{l}\text { The number of people } \\
\text { increased by } 1 \text { year }\end{array}$ & & & & & \\
\hline
\end{tabular}

b. To choose some additional values for rows of "existing people", which of the following numbers would you choose? $50,500,1000,3000,4500, \ldots$

c. Determine the rule for number sequences in the table and find the number of people increasing when commune A has 5000 people?

2. Solve the following problem by making a table:

"Students of Class 5/1 go to charity at Hematology Hospital. They need to buy 200 bo xes of milk. Known that in a supermarket, if buying 5 boxes of milk, they get 1 free. What is the total number of milk boxes they need to buy?"

\section{REFERENCES}

[1] Dougherty, B., Bryant, D. P., Bryant, B. R., \& Shin, M. (2017). Helping students with Mathematics difficulties understand ratios and proportions. Teaching Exceptional Children, 49(2), 96-105.

[2] Hoan, Đ.Đ. (editor), Ang, N., An, Đ.T., Chung, V.Q., 
\&Thuy, V.D. (2014).Toán 5. Vietnam Education Publish House, Hanoi.

[3] Juli, K. D., Edward, B. B., Steven, J.L., Matthew, R.L., \&Martha, E.S.M. (2015). GoMath(Grade 5, textbook). Houghton Mifflin Harcourt publishing company, USA.

[4] Juli, K. D., Matt, L., Miriam, A. L., \& Thomasenia, L. A. (2012). GoMath(Grade 6, textbook). Houghton Mifflin Harcourt publishing company, USA.

[5] Loc, N.P. (2016). Tích cực hóa hoạt động học tập của học sinh trong dạy học môn Toán.Can Tho University Publish House, Vietnam.

[6] Mulligan, J. \& Mitchelmore, M. (2009), Awareness of Pattern and Structure in early Mathematical development. Mathematics Education Research Journal, 21(2), 33-49.

[7] National Council of Teachers of Mathematics (2000). Principles and Standards for School Mathematics. Reston. VA: NTCM.

[8] New Jersey Mathematics Curriculum Framework (1997). Standard 11 - Patterns, relationships, and functions, 35-369.

[9] Seifi, M., Haghverdi, M., \& Azizmohamadi, F. (2012). Recognition of Students' Difficulties in Solving Mathematical Word Problems from the Viewpoint of Teachers. Journal of Basic and Applied Scientific Research, 2(3), 2923-2928. 